\title{
Reticulocyte Volume Distribution Width
}

National Cancer Institute

\section{Source}

National Cancer Institute. Reticulocyte Volume Distribution Width. NCI Thesaurus. Code C139074.

A measurement of the volume dispersion within a reticulocyte population in a biological specimen, derived from flow cytometric pulse-height analysis and expressed as either coefficient of variation or standard deviation. 